\title{
Evaluation of the long-lasting insecticidal net Interceptor $L N$ : laboratory and experimental hut studies against anopheline and culicine mosquitoes in northeastern Tanzania
}

Robert Malima', Patrick K Tungu', Victor Mwingira', Caroline Maxwell², Stephen M Magesa', Harparkash Kaur², Matthew J Kirby ${ }^{2}$ and Mark Rowland ${ }^{2^{*}}$

\begin{abstract}
Background: Long lasting insecticidal nets $(\mathrm{LN})$ are a primary method of malaria prevention. Before new types of LN are approved they need to meet quality and efficacy standards set by the WHO Pesticide Evaluation Scheme. The process of evaluation has three phases. In Phase I the candidate LN must meet threshold bioassay criteria after 20 standardized washes. In Phase II washed and unwashed LNs are evaluated in experimental huts against wild, free flying anopheline mosquitoes. In Phase III the LN are distributed to households in malaria endemic areas, sampled over three years of use and tested for continuing insecticidal efficacy. Interceptor ${ }^{\circledR}$ LN (BASF Corporation, Germany) is made of polyester netting coated with a wash resistant formulation of alpha-cypermethrin.

Methods: Interceptor LN was subjected to bioassay evaluation and then to experimental hut trial against pyrethroid-susceptible Anopheles gambiae and An. funestus and resistant Culex quinquefasciatus. Mosquito mortality, blood feeding inhibition and personal protection were compared between untreated nets, conventional alpha-cypermethrin treated nets (CTN) washed 20 times and LNs washed 0, 20 and 30 times.

Results: In Phase I Interceptor LN demonstrated superior wash resistance and efficacy to the CTN. In the Phase II hut trial the LN killed 92\% of female An. gambiae when unwashed and 76\% when washed 20 times; the CTN washed 20 times killed 44\%. The LN out-performed the CTN in personal protection and blood-feeding inhibition. The trend for An. funestus was similar to An. gambiae for all outcomes. Few pyrethroid-resistant $C x$. quinquefasciatus were killed and yet the level of personal protection (75-90\%) against Culex was similar to that of susceptible An. gambiae (76-80\%) even after 20 washes. This protection is relevant because CX. quinquefasciatus is a vector of lymphatic filariasis in East Africa. After 20 washes and 60 nights' use the LN retained 27\% of its initial insecticide dose.

Conclusions: Interceptor LN meets the approval criteria set by WHO and is recommended for use in disease control against East African vectors of malaria and filariasis. Some constraints associated with the phase II evaluation criteria, in particular the washing procedure, are critically reviewed.
\end{abstract}

Keywords: Long-lasting insecticidal net, LN, Interceptor LN, Anopheles gambiae, Anopheles funestus, Culex quinquefasciatus, Experimental hut

\footnotetext{
* Correspondence: mark.rowland@lshtm.ac.uk

${ }^{2}$ Faculty of Infectious and Tropical Diseases, London School of Hygiene \&

Tropical Medicine, WC1E 7HT London, UK

Full list of author information is available at the end of the article
} 


\section{Background}

Long lasting insecticidal nets (LN) are an ideal method of preventing malaria in Africa south of the Sahara and many Asian countries [1,2]. They provide good protection against mosquito bites when used regularly [3], they are relatively cheap compared to other methods of personal protection [3], they are simple to distribute to communities [4], and they are popular [2]. The market for LN has burgeoned in recent years. To ensure that LN competing for the market are fit for purpose the World Health Organization, through its Pesticide Evaluation Scheme (WHOPES), has set standards of quality and efficacy that require threshold criteria to be met or surpassed, regardless of the type of netting material, mode of manufacture, pyrethroid compound and long lasting formulation. In order for any new LN to enter the market or be considered for tender by the main institutional buyers, it must attain WHOPES recommendation, which means in practice passing through a process of efficacy evaluation that has three phases $[5,6]$. During the Phase I evaluation the candidate LN must, after determination of regeneration time, show efficacy in mosquito bioassay over 20 standardized washes. During Phase II, standardized washed and unwashed LN are evaluated against host seeking, free flying mosquitoes in experimental huts. At this juncture the LN may attain interim recommendation from WHOPES [5]. Phase III evaluation requires the $\mathrm{LN}$ to meet performance criteria after 3 years of use with families living in malaria endemic areas [6].

Interceptor is a LN developed and produced by BASF Corporation. The netting is a polyester fibre coated with a proprietary polymer containing the insecticide alphacypermethrin at $200 \mathrm{mg} / \mathrm{m}^{2}$. The polymer binds to the fibre and can withstand multiple washings, the active ingredient diffusing in a controlled manner to the surface of the polymer coat to maintain insecticidal efficacy [7-9].

This paper reports upon Phase I laboratory and Phase II experimental hut evaluations of Interceptor LN. The laboratory bioassays were conducted in the U.K. using laboratory-reared pyrethroid-susceptible Anopheles stephensi mosquitoes. The hut trials were undertaken at the National Institute for Medical Research (NIMR) in Muheza, northeastern Tanzania, against wild free-flying An. gambiae, An. funestus and Culex quinquefasciatus mosquitoes.

\section{Methods}

\section{Phase I}

\section{Nets and washing process}

Interceptor LN nets were supplied by BASF Corporation (Ludwigshaven, Germany). The polyester net was treated with alphacypermethrin (coated onto filaments) at a target dose of $6.7 \mathrm{~g} \mathrm{AI} / \mathrm{kg}$ of netting material for 75-denier yarn, corresponding to $200 \mathrm{mg}$ of alpha-cypermethrin per square metre of the polyester fabric (with a tolerance limit of $\pm 25 \%$ ). Polyester nets of the same denier and source were treated by hand with an aqueous solution of alphacypermethrin (Fendona 10SC, BASF) at target dosages of $25 \mathrm{mg} / \mathrm{m}^{2}$ (hereafter CTN25) and $200 \mathrm{mg} / \mathrm{m}^{2}$ (CTN200) for use as positive controls. The washing procedure for Phase I testing of LNs followed the WHOPES guidelines $[5,6]$. Netting pieces $(25 \mathrm{~cm} \times 25 \mathrm{~cm})$ were subjected to standardized washing for intervals of 5, 10, 15 and 20 times, with a one day interval between washes, using WHO-approved soap solution (Savon de Marseille) at $2 \mathrm{~g} / \mathrm{L}$ in deionized water at $30^{\circ} \mathrm{C}$ for 10 minutes in a shaker water bath set at 155 movements per minute. Pieces were then rinsed twice for 10 minutes in clean water.

\section{Three minute exposure (ball) bioassays}

Netting pieces were fixed to a metal frame consisting of two interlocking rings of $11.5 \mathrm{~cm}$ diameter [5,10]. Ten 2-5 day old unfed female Anopheles stephensi (Beech: pyrethroid-susceptible strain) mosquitoes were exposed for 3 minutes then transferred to holding cups and supplied with a $10 \%$ glucose solution. The number knocked down was recorded after 60 minutes and the number dead after 24 hours. Test conditions were $25 \pm 2^{\circ} \mathrm{C}$ and $80 \pm 5 \%$ RH throughout.

\section{Median knockdown time bioassay}

In a separate series of assays, eleven 2-5 day old unfed females were introduced into the netted frame, and as each mosquito was knocked down it was removed using an aspirator. Knockdown was defined as either collapsed against the netting or fallen to the base, and not moving. The time for the median mosquito (6th) to be knocked down was the end point of the test $[5,10]$.

\section{Chemical analysis}

Alpha-cypermethrin content of unwashed and washed nets was determined from net samples measuring $5 \mathrm{~cm}$ $\times 5 \mathrm{~cm}$ using the method described by Yates et al. [11]. Alpha-cypermethrin was extracted using acetonitrile and injected onto HPLC (Dionex Summit, Camberly, Surrey, UK), separated on a $120 \AA$ column, eluted with a 9:1 solution of water:acetonitrile and passed through a PDA100 detector at $275 \mathrm{~nm}$. From the calibration curve the amount of alpha-cypermethrin on the netting pieces was estimated and the dosage per $\mathrm{m}^{2}$ calculated.

\section{Phase II}

\section{Study area and experimental huts}

The experimental hut trial was conducted at the NIMR Field Station at Zeneti, Muheza, in northeastern Tanzania $\left(5^{\circ} 13^{\prime} \mathrm{S}\right.$ and $\left.38^{\circ} 39^{\prime} \mathrm{E}\right)$ where An. gambiae s.s. and $A n$. funestus are the major malaria vectors, and 
Culex quinquefasciatus is also common. An. gambiae s.s. at the Zeneti site are susceptible to pyrethroids but Cx. quinquefasciatus showed resistance, conferred by enhanced oxidase and site insensitivity mechanisms [12]. Confirmation of the resistance status of the wild adult mosquitoes was established during the trial by testing with alpha-cypermethrin $0.05 \%$ papers in WHO test kits [13].

The huts were constructed to a design described by WHO [13], based on the original verandah-hut design developed in Tanzania $[14,15]$. Minor modifications included a reduced eave gap of $2 \mathrm{~cm}$, a ceiling, and a concrete floor surrounded by a water filled moat. The working principle of these huts has been described previously $[10,16]$. In brief, the huts had open eaves with veranda traps and window traps on each side. Two of the verandas were closed to capture any mosquitoes that exited via the eaves, and the two other verandas were left open so mosquitoes could enter the huts through the eaves. Each night's collection inside the two screened veranda traps was multiplied by two and added to the room and window trap collections; the multiplication was designed to adjust for unrecorded escapes through the two open sides. At the end of each week the north and south verandas were closed and east and west verandas opened, or vice versa, to compensate for possible selective exiting in one compass direction.

\section{Net preparation}

The Interceptor LN, untreated nets and alphacypermethrin insecticide (Fendona 10SC) were supplied by BASF. All nets were 75 denier polyester and measured $2 \mathrm{~m}(\mathrm{~L}) \times 1.2 \mathrm{~m}(\mathrm{~W}) \times 1.5 \mathrm{~m}(\mathrm{H})$. To simulate wear and tear a total of six $4 \mathrm{~cm} \times 4 \mathrm{~cm}$ holes were cut into each net (two holes on each side and one hole at each end). The target concentration of alphacypermethin on the LNs and CTNs was $200 \mathrm{mg} / \mathrm{m}^{2}$. The LNs and CTNs were washed according to WHO Phase II washing protocols [5]. Each net was washed individually in 10 litres of tap water containing $2 \mathrm{~g}$ /litre of soap ('Savon de Marseille'), subjected to 20 rotations per minute for $6 \mathrm{~min}$ during a 10 min immersion, then rinsed twice. The interval between washes was 1 day which is the established regeneration time for Interceptor LN [9]. The washing schedule was stepped to ensure that the final wash of all treatment arms was completed on the same day.

The CTN washed to the 'point of insecticide exhaustion' served as a positive control against which to assess Interceptor LN performance. The point of insecticide exhaustion, as defined by $\mathrm{WHO}$, is the point at which the net causes less than $80 \%$ mortality and 95\% knock down in WHO cone bioassays conducted after each wash [5]. Determination of the 'point of exhaustion' was carried out by exposing unfed $A n$. gambiae s.s. Kisumu in 10 replicates of 5 mosquitoes after each wash interval on the five panels of each net. Exposure was for $3 \mathrm{~min}$, knockdown was scored after $60 \mathrm{~min}$ and mortality was scored $24 \mathrm{~h}$ later. The mortality on the alpha-cypermethrin CTN fell below $80 \%$ after 20 washes. On this occasion we opted to use a CTN washed 20 times as an appropriate control for the LN washed 20 times since the two treatment arms were both washed the same number of times.

\section{Experimental hut study design}

The following five treatment arms were tested in the huts:

1. Unwashed Interceptor LN

2. Interceptor LN washed 20 times

3. Interceptor $\mathrm{LN}$ washed 30 times, in accordance with the manufacturer's claim for wash fastness

4. Polyester net conventionally treated with alpha-cypermethrin at $200 \mathrm{mg} / \mathrm{m}^{2}$ and washed 20 times

5. Untreated unwashed polyester net

The primary outcomes were:

1. Deterrence - the reduction in entry into treatment hut relative to the control huts (i.e. those containing untreated nets);

2. Treatment-induced exiting - the proportion of mosquitoes found in exit traps of treatment huts relative to the same proportion in control huts;

3. Mortality - the proportion of mosquitoes killed relative to the total catch size;

4. Overall killing effect - the numbers killed by a treatment relative to the untreated control, as derived from the formula

$$
\text { killing effect }(\%)=100 \frac{(K t-K u)}{T u}
$$

where $K t$ is the number killed in the huts with treated nets, $K u$ is the number dead in the huts with untreated nets, and $\mathrm{Tu}$ is the total entering the huts with untreated nets.

1. Blood-feeding inhibition - the proportional reduction in blood feeding in huts with treated nets relative to controls with untreated nets

2. Personal protection - the reduction in mosquito biting by treated nets relative to untreated nets, as derived from the formula

$\%$ personal protection $=100 \frac{(B u-B t)}{B u}$

where $B u$ is the total number blood-fed mosquitoes in the huts with untreated nets, and $B t$ is the total number blood-fed in the huts with treated nets. 
Each morning dead and live mosquitoes were collected from the verandahs, room and window traps. Live mosquitoes were provided with $10 \%$ sugar solution. Delayed mortality was recorded after $24 \mathrm{~h}$. Mosquitoes were identified to species and gonotrophic status was recorded as unfed, blood-fed, semi-gravid or gravid. Random samples of An. gambiae s.l. $(\mathrm{n}=60)$ were identified to species by PCR [17].

The criteria for efficacy was that the Interceptor LN washed 20 times should perform equal to or better than the CTN washed until just before exhaustion. Twenty washes is set by WHO as an approximate number of washes a LN is likely to incur during its lifetime.

The trial took place between May and August 2006. The treatment arms were rotated twice through each hut according to a Latin Square design. A treatment was assigned at random to a particular hut for 6 nights' observation before being transferred to the next hut. Between 19:30 and 6:30 hours adult male volunteers slept on beds under the nets. The same five sleepers were rotated through the huts on consecutive nights. Six nets were available per treatment arm and each net was tested on consecutive nights during the six-night rotation. At the end of the weekly rotation the huts were cleaned and aired for one day before starting the next rotation. Data were collected for 60 nights.

\section{Chemical analysis}

Netting samples were taken for determination of alphacypermethrin content by HPLC on three occasions: before

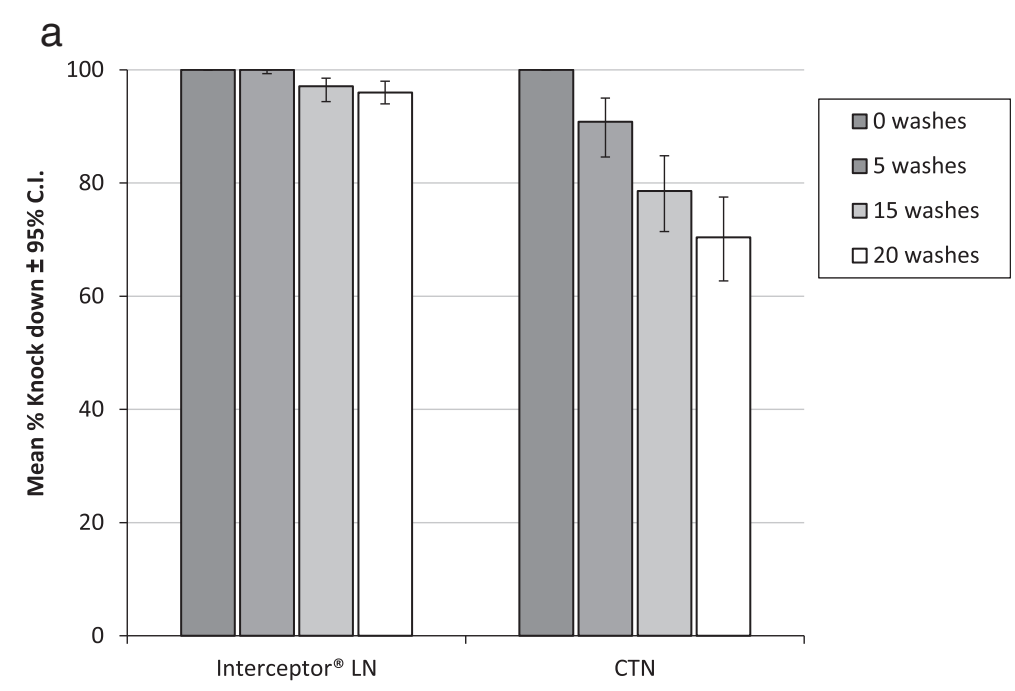

b

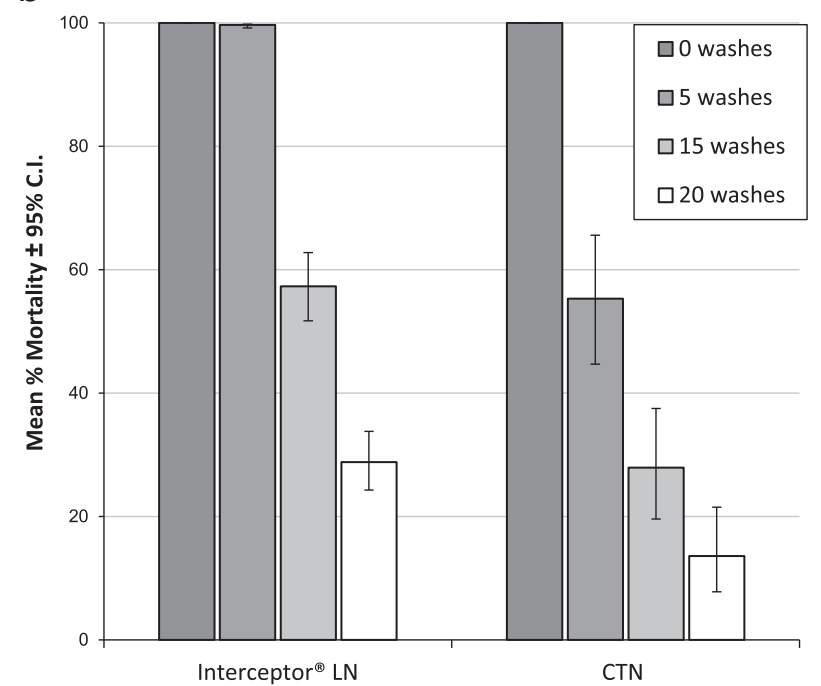

Figure 1 Response of Anopheles stephensi exposed in 3 minute ball bioassays to Interceptor LN and alpha-cypermethrin CTN25: a. Knockdown. b. Mortality. 
washing, after completion of the washes, and after conclusion of the trial as described by WHO [5]. Four netting pieces, each measuring $10 \mathrm{~cm} \times 10 \mathrm{~cm}$, were cut from the sides, end and top before and after washing from a 7 th net taken from each study arm (these nets were not used in the hut trial), while a net taken from the huts from each study arm was sampled at the end of the trial. HPLC analyses were carried out on each piece as described for Phase I assays, the average amount of alpha-cypermethrin estimated and the dosage per $\mathrm{m}^{2}$ calculated.

\section{Ethical clearance}

Ethical clearance was obtained from the Ethics Committees of the National Institute for Medical Research Tanzania (Ref: NIMR/HQ/R.8a/Vol X/86), and the London School of Hygiene and Tropical Medicine (Ref: 8589). Written informed consent was obtained from all volunteers participating in the study. The risks of malaria were explained and all volunteers were provided with chemoprophylaxis. During the trial each volunteer was monitored daily for fever or possible adverse effects due to the LNs or CTNs.

\section{Analysis}

The principal aim was to compare the efficacy of Interceptor LN washed 0 and 20 times to a CTN washed until 'exhaustion'. The key outcomes were the overall proportions of mosquitoes blood-feeding or dying relative to the untreated control. Logistic regression was used to estimate proportional outcomes of treatments (mortality, blood-feeding, exiting), and negative binomial regression was used to analyze counts of mosquitoes entering the huts (personal protection, overall insecticidal effects), after adjusting for clustering by day and for variation between individual sleepers and hut position. Laboratory bioassay data was analysed using logistic regression. Median knock down tests and chemical analysis was analysed using analysis of variance.

\section{Results}

Phase I - laboratory tests

Ball bioassay tests: Bioassay tests were done on Interceptor LN and CTN25 $\left(25 \mathrm{mg} / \mathrm{m}^{2}\right)$. The percentage knockdown of An. stephensi decreased from 100\% to $70 \%$ on exposure to the CTN25 washed 0 and 20 times ( $\mathrm{p}=0.01$ ) and from $100 \%$ to $96 \%$ on exposure to the LN washed 0 and 20 times $(\mathrm{p}=0.03)$ (Figure 1a). Percentage mortality was $55 \%$ on the CTN25 and $99 \%$ on the LN after 5 washes, and decreased to $14 \%$ and $29 \%$ respectively after 20 washes $(\mathrm{p}=0.01)$ (Figure 1b).

Median knock down tests (MKDT): After each sequence of washes median knockdown time was extended, indicating the removal of surface insecticide. At each wash point MKDT took longer on the CTN25 than on the Interceptor LN indicating a lower surface concentration of insecticide on the CTN25 ( $\mathrm{p}=0.01$ ) (Figure 2). There was correlation between percentage knockdown and the dosage of insecticide remaining on the netting after washing $\left(r^{2}=0.46\right.$, $\mathrm{p}<0.001)$ and between percentage mortality and dosage remaining $\left(\mathrm{r}^{2}=0.61, \mathrm{p}=0.001\right)$.

Chemical analysis: The alpha-cypermethrin content of the Interceptor LN decreased by $21 \%$ after 5 washes, from $209 \mathrm{mg} / \mathrm{m}^{2}$ to $166 \mathrm{mg} / \mathrm{m}^{2}$, and by $74 \%$ after 20 washes to $55 \mathrm{mg} / \mathrm{m}^{2}$ (Figure 3). The content of the CTN25 and CTN200, initially treated with $25 \mathrm{mg} / \mathrm{m}^{2}$ and $200 \mathrm{mg} / \mathrm{m}^{2}$, fell by $93 \%$ and $96 \%$ respectively after just 5 washes and by the 15th wash no alphacypermethrin was detectable by HPLC on either net.

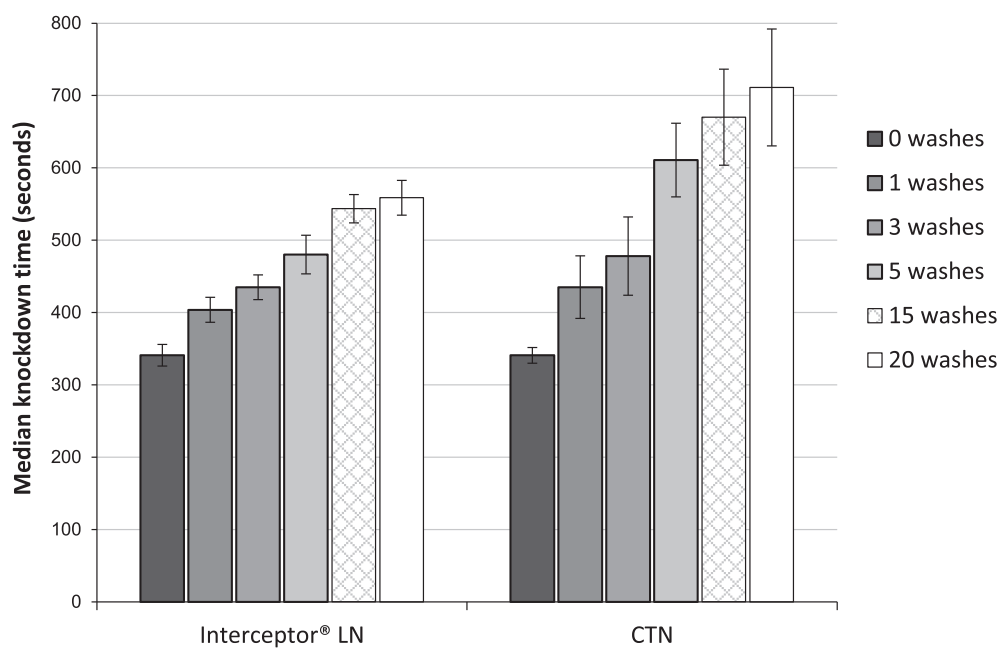

Figure 2 Median time to knockdown of Anopheles stephensi exposed in 3 minute ball bioassays to Interceptor LN and alpha-cypermethrin CTN25. 


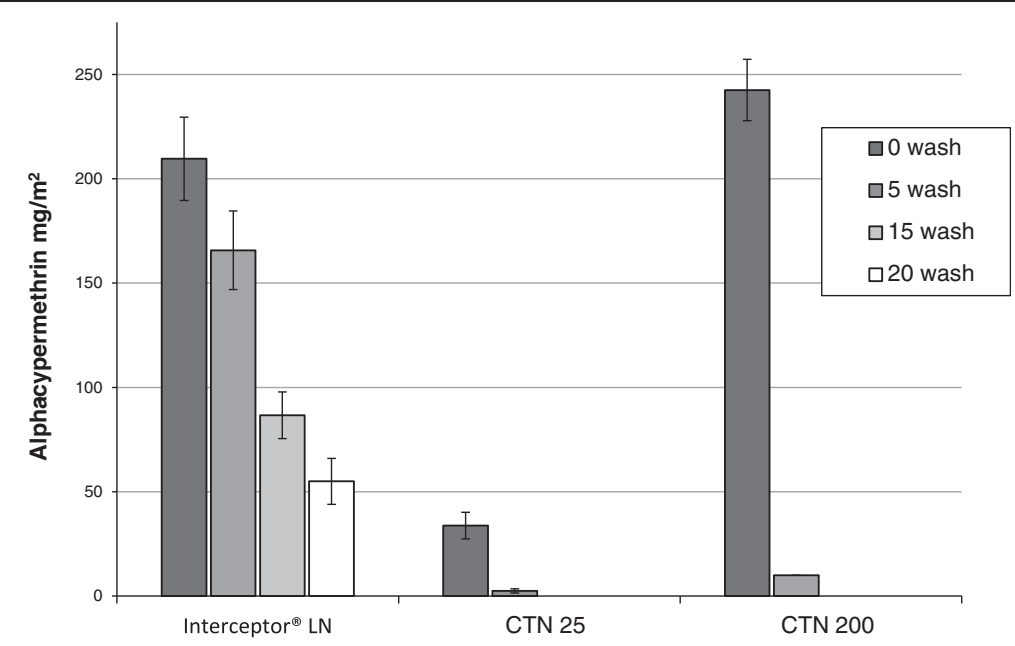

Figure 3 Chemical analysis of Phase I nets.

Phase II - experimental hut trial Insecticide susceptibility

Susceptibilty tests using WHO kits confirmed full susceptibility to alphacypermethrin in An gambiae (100\% mortality, N=351) and An funestus (100\% mortality, $\mathrm{N}=401)$. Culex quinquefasciatus were resistant to pyrethroid (52\% mortality, $\mathrm{N}=234$ ) and the ratio of time to $50 \%$ knockdown compared to a laboratory susceptible strain (TPRI) was 5.1 (95\% confidence interval: $4.2-6.0$ ).

\section{Mosquito entry into the huts}

A total of 1,836 female mosquitoes were collected over the 66 nights of the trial (Table 1). These consisted of 834 (45.4\%) Anopheles gambiae, 440 (24.0\%) An. funestus and $562(30.6 \%)$ Culex quinquefasciatus. The mean number caught per night was 12.6 An. gambiae, 6.7 An. funestus and $8.5 \mathrm{Cx}$. quinquefasciatus. There was no clear evidence of deterred entry associated with any of the treatments (Table 1). Relative to the untreated net there were fewer An. gambiae in huts with the unwashed LN and LN washed 20 times but this trend was not apparent for the other species or for the CTN treatment.

\section{Blood feeding inhibition and personal protection}

Blood feeding rates in huts with the holed untreated nets ranged from 32.1\% for An. funestus, 45.6\% for An. gambiae and $52.1 \%$ for $C x$. quinquefasciatus (Figure 4). Relative to the untreated nets the blood feeding rates through the unwashed LN was $2.0(32.1 \% / 16.2 \%)$ times less for An. funestus, 2.9 (45.6\%/11.9\%) times less for An. gambiae and $9.8(52.1 \% / 5.3 \%)$ times less for Cx. quinquefasciatus. The percentage blood feeding inhibition associated with unwashed LN was $49.6 \%, 73.8 \%$ and $89.8 \%$ respectively against these species (Table 2). The blood feeding rates with the LN washed 20 times did not differ significantly from the unwashed LN, and the levels of blood feeding inhibition also hardly changed. After 30 washes there were significant increases in percentage blood feeding relative to the unwashed LN; however, even after 30 washes the blood-feeding rates were still 50\% less for An. gambiae, $64 \%$ less for Cx. quinquefasciatus and $25 \%$ less for

Table 1 Number of wild mosquitoes entering the experimental huts during the trial of Interceptor LN

\begin{tabular}{|c|c|c|c|c|c|}
\hline & Untreated net $0 \mathrm{~W}$ & Interceptor $0 \mathrm{~W}$ & Interceptor $\mathbf{2 0 ~ W}$ & Interceptor $30 \mathrm{~W}$ & CTN $20 \mathrm{~W}$ \\
\hline \multicolumn{6}{|l|}{ Anopheles gambiae } \\
\hline Total females caught & 171 & 134 & 122 & 183 & 224 \\
\hline Average catch per night & $2.8^{\mathrm{a}}$ & $2.2^{\mathrm{b}}$ & $2.0^{\mathrm{b}}$ & $3.0^{\mathrm{a}}$ & $3.7^{c}$ \\
\hline \multicolumn{6}{|l|}{ Anopheles funestus } \\
\hline Total females caught & 81 & 68 & 87 & 79 & 125 \\
\hline Average catch per night & $1.3^{\mathrm{a}}$ & $1.1^{\mathrm{a}}$ & $1.4^{\mathrm{a}}$ & $1.3^{\mathrm{a}}$ & $2.1^{\mathrm{b}}$ \\
\hline \multicolumn{6}{|l|}{ Culex quinquefasciatus } \\
\hline Total females caught & 95 & 95 & 106 & 106 & 160 \\
\hline Average catch per night & $1.6^{\mathrm{a}}$ & $1.6^{\mathrm{a}}$ & $1.8^{\mathrm{a}}$ & $1.8^{\mathrm{a}}$ & $2.7^{b}$ \\
\hline
\end{tabular}

Numbers in the same row sharing a letter superscript do not differ significantly $(P>0.05)$. 


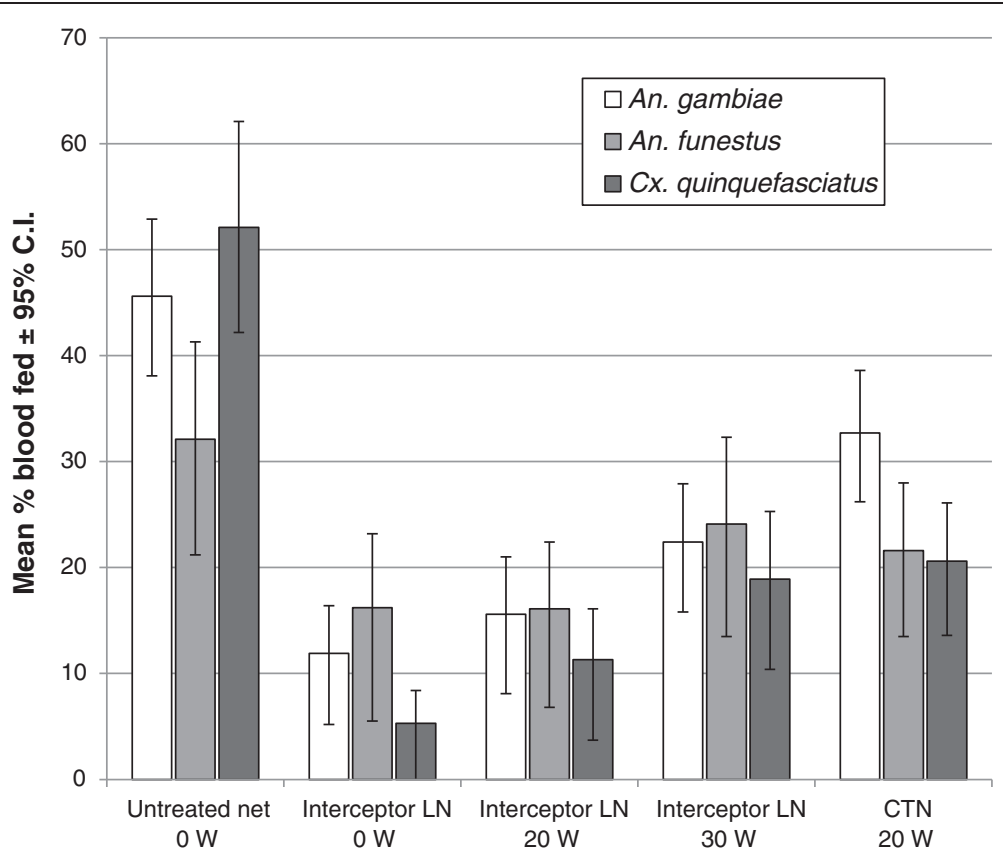

Figure 4 Blood feeding success in experimental huts with Interceptor LN and alpha-cypermethrin CTN versus untreated control.

An. funestus for the LN relative to the untreated net (Table 2). The percentage blood feeding inhibition associated with the CTN washed 20 times was significantly less than for the LN washed 20 times with respect to An. gambiae $(\mathrm{p}=0.01)$ and $C x$. quinquefasciatus $(\mathrm{p}=0.01)$ but not to $A n$. Funestus, owing to the lower abundance.

Personal protection examines the relative number of mosquitoes that blood feed in the presence of treated nets compared to untreated nets. Because there was little or no deterrence associated with the alpha-cypermethrin treated nets the levels of percentage personal protection were quite similar to percentage blood feeding inhibition of each treatment. Personal protection with the unwashed LN and the LN washed 20 times was over $75 \%$ against $A n$. gambiae and Cx. quinquefasciatus, and over $45 \%$ against An. funestus. There was no evidence of personal protection from the CTN washed 20 times against the anophelines.

\section{Mortality and overall killing effect}

The unwashed Interceptor LN killed 91.9\% of An. gambiae that entered the hut (Figure 5, Table 3). This fell to $76.2 \%$ mortality after 20 washes and to $60.0 \%$ after 30 washes.

Table 2 Blood-feeding inhibition and personal protection rates due to Interceptor LN and CTN in the experimental hut trial

\begin{tabular}{|c|c|c|c|c|c|}
\hline & Untreated net $0 \mathrm{~W}$ & Interceptor $0 \mathrm{~W}$ & Interceptor 20 W & Interceptor $30 \mathrm{~W}$ & CTN $20 \mathrm{~W}$ \\
\hline \multicolumn{6}{|l|}{ Anopheles gambiae } \\
\hline Total blood fed & 78 & 16 & 19 & 41 & 73 \\
\hline$\%$ Blood feeding inhibition & $0^{a}$ & $73.8^{\mathrm{b}}$ & $65.8^{\mathrm{bc}}$ & $50.9^{c}$ & $28.3^{d}$ \\
\hline$\%$ Personal Protection & $0^{\mathrm{a}}$ & $79.5^{\mathrm{b}}$ & $75.6^{b}$ & $47.4^{c}$ & $6.4^{\mathrm{a}}$ \\
\hline \multicolumn{6}{|l|}{ Anopheles funestus } \\
\hline Total blood fed & 26 & 11 & 14 & 19 & 27 \\
\hline$\%$ Blood feeding inhibition & $0^{a}$ & $49.6^{b}$ & $49.8^{b}$ & $24.9^{a b}$ & $32.7^{\mathrm{ab}}$ \\
\hline \% Personal Protection & $0^{a}$ & $57.7^{b}$ & $46.2^{b}$ & $26.9^{b}$ & $0^{a}$ \\
\hline \multicolumn{6}{|l|}{ Culex quinquefasciatus } \\
\hline Total blood fed & 49 & 5 & 12 & 20 & 33 \\
\hline$\%$ Blood feeding inhibition & $0^{a}$ & $89.8^{b}$ & $78.3^{b c}$ & $63.7^{c d}$ & $60.4^{d}$ \\
\hline$\%$ Personal Protection & $0^{a}$ & $89.8^{b}$ & $75.5^{b c}$ & $59.2^{c}$ & $32.7^{d}$ \\
\hline
\end{tabular}

Numbers in the same row sharing a letter superscript do not differ significantly $(P>0.05)$. 


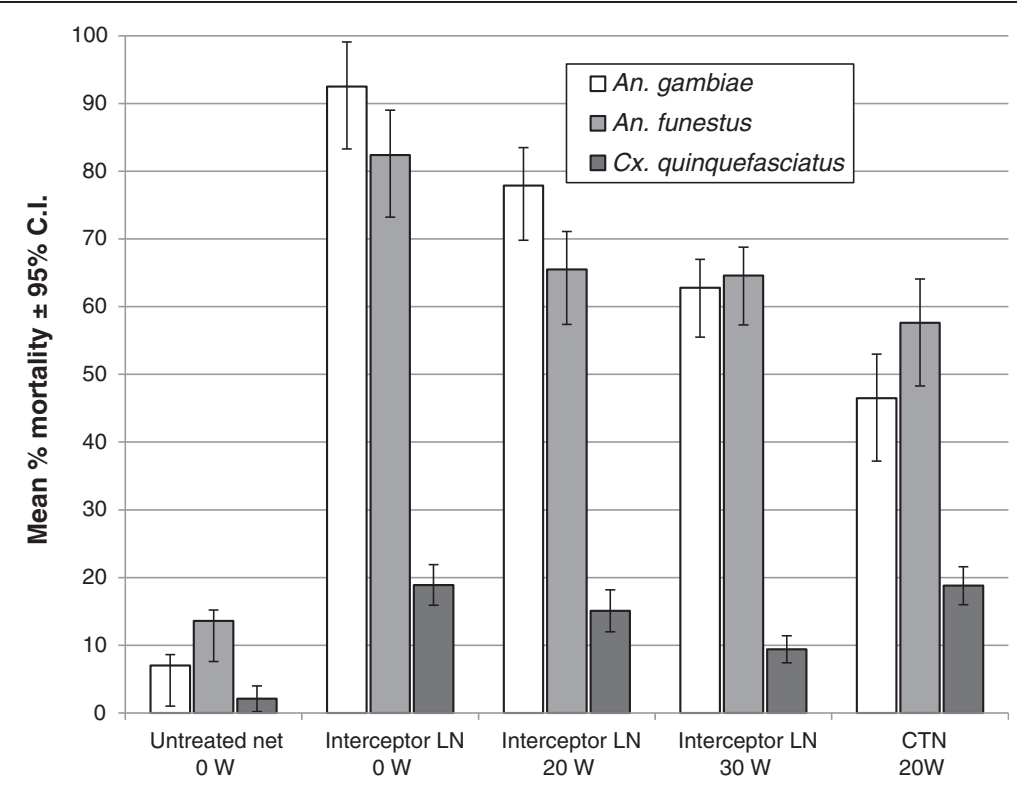

Figure 5 Mortality rates in experimental huts with Interceptor LN and CTN versus untreated control.

This observed decline in efficacy was statistically significant $(\mathrm{p}=0.001)$. The mortality induced by Interceptor LN washed 20 times was significantly higher than the mortality induced by the alpha-cypermethrin CTN washed 20 times $(\mathrm{p}=0.01)$. An. funestus showed similar trends but with lower rates of mortality compared to An. gambiae for the Interceptor treatments (Figure 5, Table 3). The difference in mortality between the Interceptor LN washed 20 times and the CTN washed 20 times was not significant. The LNs and ITNs killed only $8-20 \%$ of Cx. quinquefasciatus, this species being resistant to pyrethroids.

The overall killing effect of the Interceptor LN against the two Anopheline species ranged between 70-50\% over 0 and 30 washes, but killed less than $20 \%$ of $C x$. quinquefasciatus even when unwashed.

\section{Exiting rates}

The majority of An. gambiae and An. funestus (>86\%) naturally exited the huts before dawn and were collected from the verandah and window traps (Table 4). The proportions exiting huts with LN were rather higher than from huts with untreated nets. In contrast to the Anophelines, around $50 \%$ of $C x$. quinquefasciatus remained in the hut each morning (Table 4). However, in huts with pyrethroid nets, between $81 \%$ and $96 \%$ of Culex were induced to exit into the traps before dawn.

Table 3 Mortality and overall killing effect of Interceptor LN in the experimental hut trial

\begin{tabular}{|c|c|c|c|c|c|}
\hline & Untreated net $0 \mathrm{~W}$ & Interceptor $0 \mathrm{~W}$ & Interceptor $20 \mathrm{~W}$ & Interceptor $30 \mathrm{~W}$ & CTN $20 \mathrm{~W}$ \\
\hline \multicolumn{6}{|l|}{ Anopheles gambiae } \\
\hline Total females dead & 12 & 124 & 95 & 115 & 103 \\
\hline$\%$ corrected mortality & $0^{a}$ & $91.9^{b}$ & $76.2^{c}$ & $60.0^{\mathrm{d}}$ & $44.2^{\mathrm{e}}$ \\
\hline$\%$ Overall killing effect & $0^{a}$ & $70.4^{b}$ & $52.2^{d}$ & $64.8^{b c}$ & $57.2^{\mathrm{cd}}$ \\
\hline \multicolumn{6}{|l|}{ Anopheles funestus } \\
\hline Total females dead & 11 & 56 & 57 & 51 & 72 \\
\hline$\%$ corrected mortality & $0^{a}$ & $79.6^{\mathrm{b}}$ & $60.1^{c}$ & $59.0^{c}$ & $50.9^{c}$ \\
\hline$\%$ Overall killing effect & $0^{a}$ & $64.3^{\mathrm{b}}$ & $65.7^{b}$ & $57.1^{b}$ & $87.1^{c}$ \\
\hline \multicolumn{6}{|l|}{ Culex quinquefasciatus } \\
\hline Total females dead & 2 & 18 & 16 & 10 & 30 \\
\hline$\%$ corrected mortality & $0^{a}$ & $17.2^{b}$ & $13.3^{b}$ & $7.5^{\mathrm{c}}$ & $17.0^{\mathrm{b}}$ \\
\hline$\%$ Overall killing effect & $0^{a}$ & $17.2^{\mathrm{bc}}$ & $15.1^{b}$ & $8.6^{b}$ & $30.1^{c}$ \\
\hline
\end{tabular}

Numbers in the same row sharing a letter superscript do not differ significantly $(P>0.05)$. 
Table 4 Percentage of mosquitoes exiting huts into verandah and window traps in the Interceptor LN experimental hut trial

\begin{tabular}{|c|c|c|c|c|c|}
\hline & Untreated net $0 \mathrm{~W}$ & Interceptor $0 \mathrm{~W}$ & Interceptor $20 \mathrm{~W}$ & Interceptor $30 \mathrm{~W}$ & CTN $20 \mathrm{~W}$ \\
\hline \multicolumn{6}{|l|}{ Anopheles gambiae } \\
\hline Total females exiting & 147 & 116 & 113 & 174 & 207 \\
\hline \% Exiting & $86.0^{\mathrm{a}}$ & $86.6^{\mathrm{a}}$ & $92.6^{\mathrm{ab}}$ & $95.6^{\mathrm{b}}$ & $92.8^{\mathrm{ab}}$ \\
\hline \multicolumn{6}{|l|}{ Anopheles funestus } \\
\hline Total females exiting & 70 & 65 & 86 & 76 & 120 \\
\hline$\%$ Exiting & $86.4^{\mathrm{a}}$ & $95.6^{\mathrm{ab}}$ & $98.9^{\mathrm{ab}}$ & $96.2^{\mathrm{ab}}$ & $96.0^{\mathrm{ab}}$ \\
\hline \multicolumn{6}{|l|}{ Culex quinquefasciatus } \\
\hline Total females exiting & 51 & 91 & 94 & 94 & 130 \\
\hline$\%$ Exiting & $54.0^{\mathrm{a}}$ & $95.8^{\mathrm{b}}$ & $88.7^{\mathrm{bc}}$ & $88.7^{\mathrm{bc}}$ & $81.2^{\mathrm{cd}}$ \\
\hline
\end{tabular}

Numbers in the same row sharing a letter superscript do not differ significantly $(P>0.05)$.

\section{Chemical analysis and bioassays on nets}

The alpha-cypermethrin content on the nets before and after washing is summarised in Table 5. Chemical analysis showed that the initial dosages of the active ingredients were below the expected dosages, both for CTN (147 $\mathrm{mg} / \mathrm{m}^{2}$ instead of $200 \mathrm{mg} / \mathrm{m}^{2}$ ) and for LN (132-142 mg/ $\mathrm{m}^{2}$ instead of $200 \mathrm{mg} / \mathrm{m}^{2}$ ). The tolerance limit of alphacypermethrin on the $\mathrm{LN}$ is $200 \mathrm{mg}$ AI per $\mathrm{m}^{2} \pm 25 \%$ [6] and, as such, the alpha-cypermethrin content in unwashed Interceptor was found to be close to the lower tolerance limit. After 20 and 30 washes the concentrations on the $\mathrm{LN}$ had decreased to $41 \mathrm{mg} / \mathrm{m}^{2}$ and $21 \mathrm{mg} / \mathrm{m}^{2}$ respectively. In contrast, the concentration in alphacypermethrin CTN was only $1-3 \mathrm{mg} / \mathrm{m}^{2}$ after 20 washes. After 60 days of use in experimental huts, further decrease of alpha-cypermethrin was not evident.

Cone bioassay tests were carried out on these same net samples before and after washing. Before washing the LN and CTN treatments both recorded $100 \%$ mortality and $100 \%$ knockdown in cone tests. After 20 washes the LN recorded 100\% mortality and 100\% knockdown and the CTN recorded $68 \%$ mortality and $33 \%$ knockdown.

\section{Discussion}

The WHO Phase II experimental hut trial demonstrated that the blood-feeding inhibition (the proportional reduction in biting / blood feeding) and percentage mosquito mortality induced by Interceptor $\mathrm{LN}$ washed 20 times was superior to that of the CTN washed to exhaustion, and therefore the LN fulfilled the WHOPES criterion of a long lasting insecticidal net [5]. On the basis of these results, which formed part of an official WHOPES evaluation, Interceptor $\mathrm{LN}$ received interim recommendation as an approved LN [9]. Earlier in 2013 the WHOPES guidelines for testing of $\mathrm{LN}$ were revised to include as a positive control a WHOPES-recommended LN with similar specifications to the candidate LN in terms of insecticide, treatment technique, netting material, and washing frequency (0 and 20 times) [6]. The revised guidelines were issued after the current trial and, indeed, Interceptor now constitutes a LN appropriate to use as a positive control against new candidate LN. Because more brands of $\mathrm{LN}$ are being submitted to WHO for recommendation, one of the purposes of the revision is to demonstrate that new candidate LN match or exceed the standards set by previously approved LN such as Interceptor. Recent WHOPES trials have included both a reference $\mathrm{LN}$ washed 20 times and a CTN washed to exhaustion as comparison arms to ensure that equivalence or superiority of the reference LN to the CTN is being maintained.

The Phase I laboratory bio- and chemical assays confirmed that the Interceptor $\mathrm{LN}$ insecticide binding process imparts strong wash-retention characteristics.

Table 5 Chemical analysis of alpha-cypermethrin on the Interceptor LN and CTN before and after washing and at the end of the experimental hut trial

\begin{tabular}{lcc}
\hline Treatment & \multicolumn{1}{c}{ Concentration of alpha-cypermethrin (mg/m ${ }^{2} \pm$ std dev) } & After washing \\
\cline { 2 - 3 } & Before washing & - \\
\hline Untreated net & - & - \\
Interceptor LN unwashed & $147 \pm 2$ & $41 \pm 5$ \\
Interceptor washed 20 times & $132 \pm 4$ & $21 \pm 1$ \\
Interceptor washed 30 times & - & $140 \pm 3$ \\
CTN washed 20 times & $144 \pm 17$ & $1.2 \pm 0.4$ \\
\hline
\end{tabular}


The laboratory washing regime stripped the alphacypermethrin from the conventionally treated net within a few washes (surface content falling from 200 to $10 \mathrm{mg} /$ $\mathrm{m}^{2}$ ) and to levels undetectable by HPLC within 15 washes. However, in bioassays on the same CTN (washed 15 times) the median mosquito was knocked down after just 11 minutes exposure and mortality reached $28 \%$ in the 3 minute bioassays. A similar finding was observed in the Phase II experimental hut trials: the CTN washed 20 times had a surface concentration of only $1.2 \mathrm{mg} / \mathrm{m}^{2}$ and yet this net was still able to kill $44 \%$ of An. gambiae and 51\% of An. funestus that entered and came into contact with it. The only explanation is that pyrethroids such as alphacypermethrin must have a strong affinity to the polyester netting fibres so that even after vigorous washing a thin layer of pyrethroid, virtually undetectable by HPLC yet sufficiently bioactive to induce knockdown and mortality, must still remain bound to the fibres.

The performance of the CTN and the level of mortality and knockdown it induced after washing, while being surprising, were still not comparable to those of the LN. Interceptor LN retained a surface concentration of over $40 \mathrm{mg} / \mathrm{m}^{2}$ after 20 washes (30 times greater than the CTN's) and induced significantly higher levels of mortality than the CTN washed the same number of times. The comparison does, however, raise some issues and limitations concerning the WHOPES Phase II process. The Phase II preparation is designed to mimic the washing practices of net owning families; it cannot mimic the myriad ways in which insecticide is removed from the nets during a lifetime of use. An important source of removal during Phase III must be the abrasion a net is subjected to daily during 3 years of household use. In contrast, the only abrasion a net is subjected to during Phase II is the stirring and mashing during the 20 preparatory washes, and the 30-40 days of use during the hut trial. For this reason a WHOPES Phase II cannot anticipate or predict the outcome of evaluation after 3 years of household use. Only a WHOPES Phase III - in which nets are distributed to householders and regathered for testing after 3 years - can show whether a LN really does justify its WHO recommendation. For this reason the Phase II trial should only lead to an interim WHO recommendation. The WHO process is best seen as a series of gates with one phase setting a standard and leading to the next phase, rather than being predictive of the outcome of the next phase. The reality of this is demonstrated in the WHO report of the Phase III evaluation of Interceptor: it achieved the efficacy criteria of a true LN after 3 years of household use, whereas the CTN fell short of the efficacy criteria within just 1 year of use [9]. The failure of the CTN within a year of Phase III would not be predicted by the relative mortality shown by the CTN washed to exhaustion and Interceptor $\mathrm{LN}$ during
Phase II. This raises the question of whether the Phase II preparatory procedure should include an accelerated abrasion process between washes that better mimics the wear and tear that a net is subjected to during a lifetime of use.

Culex quinquefasciastus and Anopheles gambiae were fully capable of feeding through holed untreated nets but when the nets were treated with pyrethroid the proportion that fed was reduced substantially, from $50 \%$ to $10-20 \%$. The level of personal protection from the LN was $75-80 \%$ for An. gambiae and 75-90\% for Cx. quinquefasciatus. The results for $A n$. gambiae were expected, the results for $C x$. quinquefasciatus results were not. This is because Tanzanian $C x$. quinquefasciatus are highly resistant to pyrethroids due to site insensitivity and oxidase mechanisms [12], less than $20 \%$ are killed by the LN or CTN, and yet very few succeeded in blood feeding. In West Africa too, pyrethroid resistant $C x$ quinquefasciatus struggle to feed through holed LNs or ITNs $[18,19]$. In contrast, where $A n$. gambiae has developed high level resistance due to a combination of $k d r$ plus cytochrome P450 mechanisms [20] the proportion that manage to blood feed through holed LNs may increase to $60 \%$ or more $[21,22]$. LN seem to lose their capacity to protect when anophelines become highly resistant yet seem to retain capacity to protect when $C x$ quinquefasciatus becomes resistant. The reason for the difference between genera is not clear but may be due to behavioural differences around the net. This is particularly relevant to East Africa because $C x$. quinquefasciatus is an important vector of lymphatic filariasis there [23]. The evidence from the present trial is that an LN will provide protection against $C x$. quinquefasciatus-borne filariasis despite the species being resistant to pyrethroids.

\section{Conclusion}

Consequent to this Phase II experimental hut trial Interceptor LN obtained interim approval from WHO and has since achieved full recommendation after Phase III trials. It is the first LN to contain the pyrethroid alpha-cypermethrin and the third LN to obtain full WHOPES approval.

\section{Competing interests}

The authors declare that they have no competing interests.

\section{Authors' contributions}

RM contributed to the study design, supervised the project, processed the data, carried out the analysis, interpreted the data and drafted the manuscript. SMM managed the project and entomological teams, participated in the design of the study, interpreted the data and contributed to drafting the manuscript. PKT and VM carried out trial and processed the collections and data. CM contributed to the study design and supervision of research, interpreted the data and critically reviewed the manuscript. MJK interpreted the data and critically reviewed the manuscript. MR contributed to study design, data analysis and interpretation and revised the manuscript All authors read and approved the final manuscript.

\section{Acknowledgements}

We are grateful to the volunteers who slept under nets in the huts and to community leaders of Zenet village for their support. We thank Joseph Myamba, Frank Magogo, Wema Sudi, Josephine Nyongole, Abdallah Telaki, 
Thobias Sikanyika, Omari Mpiri and Alison Yates for technical support to the laboratory and hut trials. The study was supported by grants from the WHO Pesticide Evaluation Scheme and Gates Malaria Partnership. We appreciate Dr Robert Farlow, Ulrich Karl and John Thomas of BASF Corporation for technical support and provision of LNs and insecticide formulations and Dr Morteza Zaim of WHOPES who arranged the Phase II evaluation. This paper is published with permission from the Director General, National Institute for Medical Research Tanzania.

\section{Author details}

'Amani Medical Research Centre, National Institute for Medical Research, P.O. Box 81, Muheza, Tanzania. ${ }^{2}$ Faculty of Infectious and Tropical Diseases, London School of Hygiene \& Tropical Medicine, WC1E 7HT London, UK.

Received: 9 September 2013 Accepted: 6 October 2013 Published: 12 October 2013

\section{References}

1. Guillet P, Alnwick D, Cham MK, Neira M, Zaim M, Heyman D, Mukelabai K: Long-lasting treated mosquito nets: a breakthrough in malaria prevention. Bull World Health Organ 2001, 79:998.

2. WHO: World Malaria Report 2012. Geneva: World Health Organisation; 2012.

3. Hill J, Lines J, Rowland M: Insecticide-treated nets. Adv Parasitol 2006, 61:77-128.

4. West P, Protopopoff N, Rowland MW, Kirby MJ, Oxborough RM, Mosha FW Malima R, Kleinschmidt I: Evaluation of a national universal coverage campaign of long-lasting insecticidal nets in a rural district in north-west Tanzania. Malaria J 2012, 11:273.

5. WHO: Guidelines for laboratory and field testing of long-lasting insecticidal nets WHO/CDS/WHOPES/GCDPP/2005.11. Geneva: World Health Organisation; 2005.

6. WHO: Guidelines for laboratory and field testing of long-lasting insecticidal mosquito nets WHO/HTM/NTDMHOPES/2013.1. Geneva: World Health Organisation; 2013

7. Banek K, Kilian A, Allan R: Evaluation of Interceptor long-lasting insecticdal nets in eight communities in Liberia. Malaria J 2011, 9:84.

8. Dev V, Raghavendra K, Singh SP, Phookan S, Khound K, Dash AP: Wash resistance and residual efficacy of long-lasting polyester netting coated with a-cypermethrin (Interceptor) against malaria-transmitting mosquitoes in Assam, northeast India. Trans R Soc Trop Med Hyg 2010, 104:273-278.

9. WHO: Report of the Tenth WHOPES Working Group Meeting. Review of Spinosad 0.5\% GR \& 12\% SC; Lambda-cyhalothrin 10\% CS; K-O Tab 1-2-3; Interceptor ${ }^{\text {TM }}$ WHO/CDS/NTD/WHOPES/2007.1. Geneva: World Health Organisation; 2007

10. Curtis CF, Myamba J, Wilkes TJ: Comparison of different insecticides and fabrics for anti-mosquito bednets and curtains. Med Vet Entomol 1996, 10:1-11.

11. Yates A, N'Guessan R, Kaur H, Akogbeto M, Rowland M: Evaluation of KO-Tab 1-2-3': a wash-resistant 'dip-it-yourself' insecticide formulation for long-lasting treatment of mosquito nets. Malaria J 2005, 4:52.

12. Khayrandish A, Wood RJ: A multiple basis for insecticide resistance in a strain of Culex quinquefasciatus from Muheza, studied as resistance declined. Bull Ent Res 1993, 83:75-86.

13. WHO: Guidelines for testing mosquito adulticides for indoor residual spraying and treatment of mosquito nets WHO/CDS/WHOPES/GCDPP/2006.3. Geneva: World Health Organisation; 2006.

14. Smith A: A verandah-trap hut for studying the house-frequenting habits of mosquitos and for assessing insecticides. I. A description of the verandah-trap hut and of studies on the egress of Anopheles gambiae Giles and Mansonia uniformis (Theo.) from an untreated hut. Bull Entomol Res 1965, 56:161-167.

15. Smith A, Webley DJ: A verandah-trap hut for studying the house-frequenting habits of mosquitoes and for assessing insecticides. III. The effect of DDT on behaviour and mortality. Bull Entomol Res 1968, 59:33-46.

16. Malima RC, Oxborough RM, Tungu PK, Maxwell C, Lyimo I, Mwingira V Mosha FW, Matowo J, Magesa SM, Rowland MW: Behavioural and insecticidal effects of organophosphate-, carbamate- and pyrethroid-treated mosquito nets against African malaria vectors. Med Vet Entomol 2009, 23:317-325.

17. Scott JA, Brogdon WG, Collins FH: Identification of single specimens of the Anopheles gambiae complex by the Polymerase Chain Reaction. Am J Trop Med Hyg 1993, 49:520-529.
18. Irish SR, N'Guessan R, Boko P, Metonnou CG, Odjo A, Akogbeto M, Rowland M: Loss of protection with insecticide-treated nets against pyrethroid-resistant Culex quinquefasciatus mosquitoes once nets become holed: an experimental hut study. Parasit Vectors 2008, 1:17.

19. Ngufor C, N'Guessan R, Boko P, Odjo A, Vigninou E, Asidi A, Akogbeto M, Rowland $\mathrm{M}$ : Combining indoor residual spraying with chlorfenapyr and long-lasting insecticidal bed nets for improved control of pyrethroid-resistant Anopheles gambiae: an experimental hut trial in Benin. Malaria J 2011, 10:343.

20. Djouaka RF, Bakare AA, Coulibaly ON, Akogbeto MC, Ranson H, Hemingway J, Strode C: Expression of the cytochrome P450s, CYP6P3 and CYP6M2 are significantly elevated in multiple pyrethroid resistant populations of Anopheles gambiae s.s. from Southern Benin and Nigeria. BMC Genomics 2008, 9:538.

21. N'Guessan R, Asidi A, Boko P, Odjo A, Akogbeto M, Pigeon O, Rowland M: An experimental hut evaluation of PermaNet 3.0, a deltamethin-piperonyl butoxide combination net, against pyrethroid-resistant Anopheles gambiae and Culex quinquefasciatus mosquitoes in southern Benin. Trans $R$ Soc Trop Med Hyg 2010, 104:758-765.

22. N'Guessan R, Corbel V, Akogbeto M, Rowland M: Reduced efficacy of insecticide-treated nets and indoor residual spraying for malaria control in pyrethroid resistance area, Benin. Emerg Infect Dis 2007, 13:199-206.

23. Simonsen PE, Mwakitalu ME: Urban lymphatic filariasis. Parasitol Res 2013, 112:35-44.

doi:10.1186/1756-3305-6-296

Cite this article as: Malima et al:: Evaluation of the long-lasting insecticidal net Interceptor $L N$ : laboratory and experimental hut studies against anopheline and culicine mosquitoes in northeastern Tanzania. Parasites \& Vectors 2013 6:296.

\section{Submit your next manuscript to BioMed Central and take full advantage of:}

- Convenient online submission

- Thorough peer review

- No space constraints or color figure charges

- Immediate publication on acceptance

- Inclusion in PubMed, CAS, Scopus and Google Scholar

- Research which is freely available for redistribution

Submit your manuscript at www.biomedcentral.com/submit
Biomed Central 